\title{
Prevalence, associated factors, and disclosure of intimate partner violence among mothers in rural Bangladesh
}

Stephen Stake ${ }^{1,2}$, Saifuddin Ahmed', Wietse Tol ${ }^{1,3}$, Salahuddin Ahmed', Nazma Begum', Rasheda Khanam', Meagan Harrison ${ }^{1}$ and Abdullah H. Baqui ${ }^{*}$ (i)

\begin{abstract}
Background: The purpose of this study is to assess the prevalence and associated factors of physical and sexual intimate partner violence (IPV) among married women of reproductive age in a rural population in northeast Bangladesh. In addition, we examined women's sharing and disclosure of violence experience with others.

Methods: This cross-sectional study uses data from a household survey of 3966 women conducted in 2014 in the Sylhet District of Bangladesh. Interviews were completed in respondent's homes by trained local female interviewers.

Results: Twenty-nine percent $(28.8 \%, 95 \% \mathrm{Cl} 27.4-30.3 \%)$ of the women reported ever experiencing physical or sexual IPV by their spouse; $13.2 \%$ (95\% Cl 12.1-14.3\%) reported physical or sexual IPV in the past year. Of the 13.2\%, 10.1\% (95\% Cl 9.2-11.1\%) reported experiencing physical IPV and 4.6\% (95\% Cl 4.0-5.3\%) reported sexual IPV. In a combined model, the adjusted odds of having experienced physical or sexual IPV in the past year were higher for women who were raised in households with history of IPV ( $A O R=4.35,95 \% \mathrm{Cl} 3.26-5.80$ ); women with no formal education ( $A O R=1.76,95 \% \mathrm{Cl} 1.30-2.37)$; women whose husbands had no formal education $(A O R=1.63,95 \% \mathrm{Cl}$ 1.22-2.17); Muslim ( $\mathrm{AOR}=1.63,95 \% \mathrm{Cl} 1.03-2.57)$; women younger than age 30 ( $\mathrm{AOR}=1.53,95 \% \mathrm{Cl} 1.11-2.12$ ); and women who were members of an $\mathrm{NGO}$ or microcredit financial organization ( $\mathrm{AOR}=1.38,95 \% \mathrm{Cl} 1.04-1.82$ ). Wealth, parity, number of household members, and pregnancy status (pregnant, postpartum, neither pregnant nor postpartum) were not associated with physical or sexual IPV after adjusting for other factors. Data on disclosure was available for women who reported experiencing physical violence in the last year; only $31.8 \%$ of victims told someone about the violence they had experienced and $1 \%$ reported to police, clerics, health workers, or a counselor altogether.
\end{abstract}

Conclusions: In rural northeast Bangladesh, a high proportion of women of reproductive age experience physical or sexual IPV. Women do not often speak of these experiences, especially to anyone outside of family. Interventions aimed at preventing future IPV and addressing current IPV should focus on women who witnessed IPV in childhood, as well as younger women and less educated couples.

* Correspondence: abaqui@jhu.edu

'Johns Hopkins Bloomberg School of Public Health, Room E-8153, 615 N.

Wolfe Street, Baltimore, MD 21205, USA

Full list of author information is available at the end of the article

(c) The Author(s). 2020 Open Access This article is licensed under a Creative Commons Attribution 4.0 International License, which permits use, sharing, adaptation, distribution and reproduction in any medium or format, as long as you give appropriate credit to the original author(s) and the source, provide a link to the Creative Commons licence, and indicate if changes were made. The images or other third party material in this article are included in the article's Creative Commons licence, unless indicated otherwise in a credit line to the material. If material is not included in the article's Creative Commons licence and your intended use is not permitted by statutory regulation or exceeds the permitted use, you will need to obtain permission directly from the copyright holder. To view a copy of this licence, visit http://creativecommons.org/licenses/by/4.0/ The Creative Commons Public Domain Dedication waiver (http://creativecommons.org/publicdomain/zero/1.0/) applies to the data made available in this article, unless otherwise stated in a credit line to the data. 
(Continued from previous page)

Trial registration: This study was registered as a Clinical Trial (Identifier: NCT01702402). https://clinicaltrials.gov/ct2/ show/NCT01702402

Keywords: Intimate partner violence, Maternal health, Mental health, Bangladesh

\section{Background}

Worldwide, it is estimated that one in three women will experience physical or sexual violence at some point in their lives, most of which will occur within the context of an intimate partner relationship [1,2]. Intimate partner violence (IPV) is a violation of human rights and carries important risks for negative impacts on physical and mental health [3]. Survivors of violence are at a higher risk for mortality, physical injury, chronic pain syndromes, depression, suicide attempts, psychosomatic disorders, gastrointestinal disorders, and reproductive health issues [4-6]. The consequences of abuse can be long lasting and the harsher and more frequent the abuse, the greater the impact on a woman's health [7-9]. Moreover, the children of women who experience IPV are also at higher risk for poor health outcomes [10-12]. Perinatal and neonatal mortality rates are significantly higher among women who experienced IPV [13].

IPV occurs across the globe, but prevalence varies between and within countries, ranging from 15 to $71 \%$ [14]. While IPV is a global problem, it disproportionately affects low and middle-income countries (LMICs). According to recent estimates by the World Health Organization (WHO), the global lifetime prevalence of physical and/or sexual violence among ever-partnered women in LMICs is 30\% [2]. For high-income countries, the prevalence is 23\% [2]. Countries of South-East Asia (WHO Region) were estimated to have the highest combined lifetime prevalence (37.7\%) out of all WHO Regions specified and Bangladesh is no exception [2]. Research findings from surveys conducted in Bangladesh are divergent and vary by region, with estimates of lifetime prevalence of physical IPV ranging between 42 and $76 \%$, and estimates of annual prevalence of physical IPV to be between 16 and 67\% [14-22].

Previous studies in Bangladesh have highlighted a number of factors associated with IPV against women. At a societal level, Bangladesh's traditional patriarchy with prescriptive gender roles assign women the primary responsibility of raising children and create a woman's economic dependence on her spouse [23]. Within classic Bangladesh patriarchy, women are married into households headed by their husbands' fathers. Women can legally select a spouse, but this is not common. Customarily, their father or elder brother selects their future spouse. Guardianship then passes from women's fathers to their spouses [24]. A wife's neglect of her inherent duties or challenge to authority is interpreted as disobedience and violence by the husband is commonly accepted as justifiable punishment [24-26]. Socioeconomic advantages including wealth and educational attainment have been associated with lower prevalence of IPV [16, 21, 24, 27-29]. Women who marry at a younger age or who are presently in a marriage with dowry demands have reported increased odds of IPV [28, 30, 31]. Studies assessing the association between IPV and employment and microfinance programs for women have demonstrated mixed findings [27, 3235]. Additional factors associated with IPV include parity, unintended pregnancy, having witnessed abuse as a child, and younger or older age [30, 36-39].

Violence against women remains largely unaddressed in many countries, including Bangladesh. Despite the large burden of IPV in Bangladesh, there is a relatively little research addressing the topic $[12,16,17,21,22,24$, $26,27,32,40]$. Even less is known about IPV in the Sylhet Division of Bangladesh, which has the lowest levels of educational attainment, highest unemployment, ranks lowest in all measures of women's empowerment, has consistently exhibited the highest total fertility rate, and is characterized by many other socioeconomic and health disparities [41].

IPV is often difficult to identify because it mostly occurs in private, victims are often fearful of disclosing IPV, and IPV frequently occurs in the contexts where legal systems and cultural norms do not treat these actions as a crime. Empowering established laws, such as the Suppression of Violence against Women and Children Act of 2000, to bring about justice for women in Bangladesh proves difficult [42]. Awareness of existing laws against IPV and support for punishments within the laws remains low [43]. Furthermore, criminal suits against offenders can be extremely expensive, and the women violated seldom have the resources to bring the violators to court $[44,45]$. In Bangladesh, many women who experience IPV remain silent about their experience $[20,40]$. Women may choose to remain silent about IPV for a number of reasons, including fear of consequences for both themselves and their children and compromising family honor [40]. Disclosure of IPV is vital for connecting victims with available resources. Moreover, understanding of disclosure patterns is needed for planning and providing context-specific programming [46]. 
In light of previous research and the socioeconomic disparities endemic to Sylhet, we hypothesized we would find a higher prevalence of physical and sexual IPV and that both educational attainment and wealth would be associated with less violence [16, 21, 27, 47]. In alignment with other research, we hypothesized women of a younger age, a history of their mother having been abused, and not belonging to an NGO would be associated with greater odds of having experienced IPV [24, 27, 30, 32]. The relationship between IPV and women's participation in NGOs and micro-financing organizations is a specific area of interest. It has been argued that organizations providing microcredit loans offer economic opportunities that might protect women against violence. Others claim that financial security empowers women, which could possibly increase friction with one's spouse and increase the risk to violence, especially in conservative areas [32]. This study aims to examine the prevalence of physical and sexual IPV, factors associated with IPV, and the disclosure patterns of married women of reproductive age in rural Sylhet, Bangladesh.

\section{Methods}

\section{Study design and setting}

The study data were obtained from face-to-face household interviews of 3966 women from a cross-sectional survey in the Sylhet District of Bangladesh. This was the endline survey of a quasi-experiment, the Healthy Fertility Study (HFS), conducted at the completion of the eight follow-up visits. Eight clusters, each with about 25, 000 population (known as unions, the smallest administrative unit in Bangladesh, with a health center), were allocated to either intervention or control to test an integrated package of maternal and newborn health and family planning $[48,49]$. The HFS was not designed to address IPV.

Beginning in December of 2007, all pregnant women identified by Community Health Workers (CHWs) in 8 unions were offered enrolment into the HFS. CHWs are locally recruited young women with an education of at least grade 10 and received 3 weeks of basic maternal and new-born health training. For all married pregnant women consenting, a baseline survey was given upon enrolment to obtain background information. Of the 4430 women recruited during pregnancy for the HFS at baseline beginning in December of 2007, 90\% $(n=3966)$ were available for the endline survey in January of 2014. Due to the nature of the parent study, all women included in the endline survey had one or more live births preceding the survey.

\section{Assessment of variables}

Trained female interviewers collected data from each study participant in her home. Socio-demographic information, such as date of birth, educational attainment, wealth (assets), and religion were collected upon enrollment into the HFS study. Wealth status was assessed at baseline by way of principal component analysis of household items. Physical and sexual IPV, the primary variables of interest in this study, were assessed during the endline survey with an instrument adapted for the 2007 Bangladesh Demographic Health Survey [22]. This modified version of the Conflict Tactics Scale was used to determine if women had experienced specific acts of physical and sexual violence. Participants were asked for a yes or no response if their husband ever did the following: (1) push you, shake you, or throw something at you; 2) slap you; 3) twist your arm or pull your hair; 4) punch you with his fist or something that could hurt you; 5) kick you, drag you or beat you up; 6) try to choke you or burn you on purpose; 7) threaten or attack you with a knife, gun, or any other weapon; 8) physically force you to have sexual intercourse with him even when you did not want to? If a participant answered "yes" to any of the aforementioned questions, they were asked if the specific violent act(s) had occurred in the last 12 months. Psychological harm (emotional abuse) was not assessed.

\section{Data quality assurance and ethics}

Data collected in paper-based forms were entered into the database using customized data entry programs that included range and consistency checks. Detection of omissions and inconsistencies between variables were built into these programs to allow for immediate detection of simple errors. Any problems identified were reported back to the field team to ensure high quality data.

All women were enrolled in the study after informed consent. Enrolled participants were free to drop out of the study at any time and were not obligated to answer survey questions. Optimally, referral systems should be in place for women who have experienced IPV. No referral system was available in Bangladesh, and the intent of including these questions in surveys was to assess the burden and risk factors of IPV so as to design future intervention. The primary study as described was approved by the Institutional Review Board of the Johns Hopkins Bloomberg School of Public Health and the National Research Ethics Committee of Bangladesh Medical Research Council (BMRC) and was registered under clinical trial registry (Identifier: NCT01702402).

\section{Statistical methods}

We estimated the prevalence of physical (items 1-7) and sexual IPV (item 8), as the proportion of women indicating having experienced any of the relevant violent acts. We included data for all women participating in the 
endline survey of 2014. Both lifetime and immediate past year estimates of each type of violence were examined.

Mixed effects logistic regression modeling was used to analyze variables associated with IPV. Mixed regression modeling takes into account community-level variables and clustering of variance that can possibly modify the relationship between the individual-level variables and IPV [32]. Factor models were constructed in a three-step sequence starting with individual factors [Model1] and hierarchically adding familial information [Model2] and membership of an NGO at the communal level [Model3]. Each model accounted for clustering to directly estimate odds ratios and standard errors [50]. Covariates including age, obstetric status, parity, education, wealth, religion, household size, historical abuse, and NGO membership were selected based on literature reviews and theoretical rationales. Analysis was conducted using the STATA (version 13) statistical package (StataCorp., 2009).

\section{Results}

\section{Prevalence of physical and sexual IPV}

Sample characteristics of the study participants by selected demographic variables with reported physical and/or sexual IPV are presented in Table 1. Twenty-nine percent (28.8\%, 95\% CI 27.4-30.3\%) of women reported having ever experienced physical or sexual IPV by their husband, with thirteen percent (13.2\%, 95\% CI 12.1-14.3\%) having experienced physical or sexual IPV in the past year. Twenty-six percent $(26.2 \%, 95 \%$ CI $24.9-27.6 \%)$ of women reported having ever experienced physical violence and ten percent $(10.1 \%, 95 \%$ CI 9.2-11.1\%) indicated physical violence had occurred in the past year. Seven percent of women (7.2\%, 95\% CI 6.4-8.0\%) reported sexual violence, with 5 percent $(4.6 \%, 95 \%$ CI $4.0-5.3 \%)$ indicating sexual violence had occurred in the past year. Specific forms of violence reported by study participants are further outlined in Table 2.

\section{Factors associated with physical and sexual IPV}

Women who witnessed their father hit or beat his wife (the mother of the interviewee) were significantly more likely to have experienced IPV in the past year (AOR = 4.35, 95\% CI 3.26-5.80) (Table 3). The odds of having experienced physical or sexual IPV in the past year were significantly higher for women with no formal education (AOR $=1.76,95 \%$ CI $1.30-2.37$ ) or $1-5$ years of education $(\mathrm{AOR}=1.54,95 \% \mathrm{CI} 1.17-2.02)$ as compared to women with 6 or more years of education. Furthermore, women whose husbands had no education were more likely to report having experienced physical or sexual IPV in the past year than women whose husbands had 6 or more years of education (AOR $=1.63,95 \%$ CI $1.22-$ 2.17). Study participants who self-identified as Muslim were significantly more likely to report having experienced physical or sexual IPV in the past year than non-Muslim women $(\mathrm{AOR}=1.63,95 \% \mathrm{CI} 1.03-2.57)$. Women younger than 30 years of age experienced a relatively higher prevalence of physical or sexual IPV in the past year (AOR = $1.53,95 \%$ CI 1.11-2.12) in comparison to those 35 years of age and older. Members of an NGO or financial organization were more likely to have experienced IPV in the past year (AOR $=1.38,95 \%$ CI 1.04-1.82).

In comparison to women of the lowest wealth quintile (poorest), women in the second lowest quintile (second poorest) were less likely to report having experienced physical or sexual IPV by their spouse (AOR $=0.71,95 \%$ CI 0.51-0.98). However, no higher wealth quintiles were significantly different from the poorest. Hence, no clear trend between wealth quintiles and IPV was detected. No significant association was detected between parity and IPV. Moreover, women who were pregnant or postpartum (up to 1 year) did not report significant differences in having experienced physical or sexual IPV in the past year. Past year prevalence of physical or sexual IPV was not significantly different between women of differing household sizes (number of persons).

\section{IPV antecedents, reporting, and perceptions}

Among women who reported physical IPV in the past year $(n=402)$, the majority $(65.2 \%)$ reported that nothing in particular prompted the physical abuse by spouses (Table 4). The most common responses given by women to the question of why physical violence in the past year occurred were financial crisis (22.9\%), disobeying their spouse or elder (21.4\%), neglecting chores (19.7\%), and refusing sex (14.8\%).

Approximately one third (31.2\%) of women who reported physical IPV in the past year $(n=402)$ told someone (Table 5). When victims did tell someone about physical abuse, they most often told their parents, inlaws, neighbors, siblings, and/or extended family. Local leaders, police, clerics, and health workers were seldom told. Nearly $90 \%$ of women who had been physically or sexually abused in the past year felt their husband treats them fairly.

\section{Discussion}

Our study documented a lifetime (28.8\%) and past year (13.2\%) prevalence of reported physical or sexual violence among married women of reproductive age in rural Sylhet District of Bangladesh. The rates are similar to globally observed rates, but lower than studies conducted in Bangladesh [14-21, 51]. According to the Bangladesh Demographic Health Survey, 2007 (BDHS, 2007), among all 8 administrative divisions of Bangladesh, Sylhet Division had the lowest reported prevalence $(41.7 \%)$ of lifetime physical or sexual IPV 
Table 1 Frequency distributions of participants according to demographic variables with reported physical and/or sexual IPV $(n=$ 3966)

\begin{tabular}{|c|c|c|c|c|c|c|c|c|c|c|}
\hline \multirow[t]{3}{*}{ Variable } & \multicolumn{4}{|c|}{ Ever during marriage } & \multirow[b]{3}{*}{$p$ value } & \multicolumn{4}{|c|}{ During past year } & \multirow[b]{3}{*}{$p$ value } \\
\hline & \multicolumn{2}{|c|}{ IPV } & \multicolumn{2}{|c|}{ No IPV } & & \multicolumn{2}{|c|}{ IPV } & \multicolumn{2}{|c|}{ No IPV } & \\
\hline & $\mathrm{n}$ & $\%$ & $n$ & $\%$ & & $\mathrm{n}$ & $\%$ & $\mathrm{n}$ & $\%$ & \\
\hline Age & & & & & 0.162 & & & & & 0.595 \\
\hline$<30$ years & 373 & 32.6 & 996 & 35.3 & & 174 & 33.5 & 228 & 31.4 & \\
\hline 30-34 years & 386 & 33.8 & 957 & 33.9 & & 154 & 31.4 & 951 & 32.7 & \\
\hline $35+$ years & 384 & 33.6 & 870 & 30.8 & & 169 & 35.1 & 1174 & 36.0 & \\
\hline Pregnancy Status & & & & & 0.473 & & & & & 0.793 \\
\hline Pregnant & 79 & 6.9 & 222 & 7.9 & & 40 & 7.7 & 261 & 7.6 & \\
\hline Postpartum $<6$ months & 76 & 6.6 & 215 & 7.6 & & 36 & 6.9 & 255 & 7.4 & \\
\hline Postpartum 6-12 months & 89 & 7.8 & 205 & 7.3 & & 44 & 8.4 & 250 & 7.3 & \\
\hline Not Pregnant nor Postpartum & 899 & 78.7 & 2181 & 77.3 & & 402 & 77.0 & 2678 & 77.8 & \\
\hline Parity (total live births) & & & & & 0.053 & & & & & 0.545 \\
\hline 1 & 239 & 20.9 & 660 & 23.4 & & 122 & 23.4 & 777 & 22.6 & \\
\hline 2 & 217 & 19.0 & 598 & 21.2 & & 99 & 19.0 & 716 & 20.8 & \\
\hline 3 & 222 & 19.4 & 528 & 18.7 & & 92 & 17.6 & 658 & 19.1 & \\
\hline $4+$ & 465 & 40.7 & 1037 & 36.7 & & 209 & 40.0 & 1293 & 37.5 & \\
\hline Mother's education & & & & & 0.000 & & & & & 0.000 \\
\hline No schooling & 476 & 41.6 & 889 & 31.5 & & 226 & 43.3 & 1139 & 33.1 & \\
\hline $1-5$ years & 393 & 34.4 & 898 & 31.8 & & 179 & 34.3 & 1112 & 32.3 & \\
\hline$>5$ years & 274 & 24.0 & 1036 & 36.7 & & 117 & 22.4 & 1193 & 34.6 & \\
\hline Husband's education & & & & & 0.000 & & & & & 0.000 \\
\hline No schooling & 554 & 48.5 & 1058 & 37.5 & & 270 & 51.7 & 1342 & 39.0 & \\
\hline $1-5$ years & 361 & 31.6 & 866 & 30.7 & & 156 & 29.9 & 1071 & 31.1 & \\
\hline$>5$ years & 228 & 19.9 & 899 & 31.8 & & 96 & 18.4 & 1031 & 29.9 & \\
\hline Household wealth quintile & & & & & 0.011 & & & & & 0.005 \\
\hline Lowest & 175 & 15.3 & 533 & 18.9 & & 89 & 17.1 & 619 & 18.0 & \\
\hline Second & 211 & 18.4 & 579 & 20.5 & & 86 & 16.5 & 704 & 20.4 & \\
\hline Middle & 264 & 23.1 & 581 & 20.6 & & 121 & 23.2 & 724 & 21.0 & \\
\hline Fourth & 255 & 22.3 & 551 & 19.5 & & 133 & 25.5 & 673 & 19.5 & \\
\hline Highest & 238 & 20.8 & 579 & 20.5 & & 93 & 17.8 & 724 & 21.0 & \\
\hline Religion & & & & & 0.003 & & & & & 0.052 \\
\hline Islam & 1089 & 95.3 & 2617 & 92.7 & & 498 & 95.4 & 3208 & 93.2 & \\
\hline Hindu/Others & 54 & 4.7 & 206 & 7.3 & & 24 & 4.6 & 236 & 6.9 & \\
\hline Father abused Mother & & & & & 0.000 & & & & & 0.000 \\
\hline Yes & 200 & 17.5 & 91 & 3.2 & & 95 & 18.2 & 196 & 5.7 & \\
\hline No & 695 & 60.8 & 2284 & 80.9 & & 297 & 56.9 & 2682 & 77.9 & \\
\hline Do not Know & 248 & 21.7 & 448 & 15.9 & & 130 & 24.9 & 566 & 16.4 & \\
\hline Members in household & & & & & 0.000 & & & & & 0.053 \\
\hline$<5$ & 356 & 31.1 & 799 & 28.3 & & 162 & 31.0 & 993 & 28.8 & \\
\hline $5-9$ & 642 & 56.2 & 1508 & 53.4 & & 292 & 55.9 & 1858 & 53.9 & \\
\hline $10+$ & 145 & 12.7 & 516 & 18.3 & & 68 & 13.0 & 593 & 17.2 & \\
\hline NGO member & & & & & 0.000 & & & & & 0.005 \\
\hline Yes & 187 & 16.4 & 303 & 10.7 & & 84 & 16.1 & 406 & 11.8 & \\
\hline No & 956 & 83.6 & 2520 & 89.3 & & 438 & 83.9 & 3038 & 88.2 & \\
\hline Total & 1143 & 28.8 & 2823 & 71.2 & & 522 & 13.2 & 3444 & 86.8 & \\
\hline
\end{tabular}


Table 2 Reported physical and sexual IPV by study participants $(n=3966)$

\begin{tabular}{|c|c|c|c|c|}
\hline \multirow[t]{2}{*}{ Type of violence } & \multicolumn{2}{|c|}{ Ever during marriage } & \multicolumn{2}{|c|}{ During past year } \\
\hline & $\mathrm{n}$ & $\%$ & $\mathrm{n}$ & $\%$ \\
\hline Any Physical or Sexual Abuse & 1143 & 28.8 & 522 & 13.2 \\
\hline Any Physical Abuse & 1040 & 26.2 & 402 & 10.1 \\
\hline Slapped & 972 & 24.5 & 362 & 9.1 \\
\hline Pushed/Shaken/Thrown At & 554 & 14.0 & 210 & 5.3 \\
\hline Twist Arm/Pulled Hair & 266 & 6.7 & 111 & 2.8 \\
\hline Punched & 365 & 9.2 & 154 & 3.9 \\
\hline Kicked/Dragged/Beaten Up & 356 & 9.0 & 154 & 3.9 \\
\hline Choked/Burned & 59 & 1.5 & 25 & 0.6 \\
\hline Threatened with Knife/Gun & 30 & 0.8 & 14 & 0.4 \\
\hline Forced Sex & 286 & 7.2 & 183 & 4.6 \\
\hline One Type of Violence & 403 & 10.2 & 201 & 5.1 \\
\hline 2-3 Types of Violence & 452 & 11.4 & 186 & 4.7 \\
\hline 4-5 Types of Violence & 229 & 5.8 & 77 & 1.9 \\
\hline 6+ Types of Violence & 59 & 1.5 & 58 & 1.5 \\
\hline
\end{tabular}

Note: Some women experienced more than one type of violence. Of the 522 women who experienced either physical or sexual IPV in the past year, 402 experienced physical IPV, 120 experienced sexual IPV, and 63 experienced both types of IPV

[22]. The finding was surprising considering that Sylhet faces the most socioeconomic and health disparities among all divisions [41]. We have observed an even lower rate than documented in BDHS. Sampling and data collection methodology was different in our study than the BDHS, which may explain why our prevalence findings for Sylhet were approximately 13\% lower than that reported by the BDHS. For the BDHS, either husbands or wives were interviewed in order to obtain estimates of IPV in the Sylheti population. Moreover, the BDHS had a comparatively smaller sample size of only 283 participants. Also, all women in our study population had young children, which could possibly be a protective factor. Furthermore, data collection in our study took place as part of an intervention. Participants may have given a more socially desirable answer for fear of not receiving services or upsetting people that provide services. Abused women in Bangladesh are often silent about experiences of violence for reasons including fear of repercussions from the abuser and compromising family honor, which can also influence study findings [40].

Women whose mother had been abused by her husband (father of interviewee) reported an astounding four-fold the odds of having experienced physical or sexual violence in the past year. It may be that fathers select a spouse for their daughter who shares common behaviors and attitudes, such as strict gender roles and justification for abuse when crossed [24]. In addition, cultural, economic, and educational similarity between families of arranged marriages might result in a transfer of patterns of abuse to the next generation. An alternative explanation of this strong relationship could be that women who are willing to admit to having been abused are also willing to admit their mother had been abused, thus strengthening the detected association.

Our findings that lower education level of both the wife and her husband were associated with experiencing higher odds of physical or sexual IPV in the past year is consistent with earlier findings from Bangladesh [16, 31]. Men with perceived power, such as a higher degree of education, may have less need to assert their dominance via IPV [52-54]. In addition, communication or cognitive skills obtained from greater educational attainment may contribute to better conflict resolution within marriage [47]. Moreover, school programming and relationships may influence attitudes towards the acceptability of violence in both males and females and thereby reduce IPV [55].

Muslim women reported a higher prevalence of physical or sexual violence within marriage in comparison to women of other religions (predominantly Hindu). Our findings in rural Bangladesh were similar to Naved's, who postulated that the difference in IPV might be explained by Muslim women traditionally having less mobility and independence than Hindu women in Bangladesh, which limits access to people and resources [27]. Specific reasons for the association between IPV and religion are inconclusive without further qualitative research.

In accord with other studies from Bangladesh, we found married women of younger ages experienced higher odds of IPV in the past year in comparison to older women of reproductive age [27, 30]. In Bangladesh, younger women are more likely to have an arranged marriage and have lower social status [56]. Though our data was not 
Table 3 Odds of physical or sexual violence by husband in the past year by selected variables (crude and mixed effects model)

\begin{tabular}{|c|c|c|c|c|c|c|c|c|}
\hline \multirow[t]{2}{*}{ Variable } & \multicolumn{4}{|c|}{ Crude OR } & \multicolumn{4}{|c|}{ Adjusted model OR } \\
\hline & \multirow[t]{2}{*}{ OR } & \multirow[t]{2}{*}{$p$ value } & \multicolumn{2}{|c|}{$95 \% \mathrm{Cl}$} & \multirow[t]{2}{*}{ AOR } & \multirow[t]{2}{*}{$p$ value } & \multicolumn{2}{|c|}{$95 \% \mathrm{Cl}$} \\
\hline \multicolumn{5}{|l|}{ Age } & & & & \\
\hline$<30$ years & 1.05 & 0.67 & 0.84 & 1.31 & 1.53 & 0.01 & 1.11 & 2.12 \\
\hline 30-34 years & 0.98 & 0.79 & 0.77 & 1.22 & 1.20 & 0.16 & 0.93 & 1.55 \\
\hline $35+$ years & \multicolumn{4}{|c|}{ Reference } & \multicolumn{4}{|c|}{ Reference } \\
\hline \multicolumn{9}{|l|}{ Pregnancy Status } \\
\hline Pregnant & 1.04 & 0.84 & 0.73 & 1.47 & 1.00 & 0.99 & 0.69 & 1.44 \\
\hline Postpartum $<6$ months & 0.97 & 0.86 & 0.67 & 1.39 & 0.97 & 0.88 & 0.66 & 1.42 \\
\hline Postpartum 6-12 months & 1.18 & 0.35 & 0.84 & 1.65 & 1.19 & 0.34 & 0.83 & 1.71 \\
\hline Not Pregnant nor Postpartum & \multicolumn{4}{|c|}{ Reference } & \multicolumn{4}{|c|}{ Reference } \\
\hline \multicolumn{9}{|l|}{ Parity (total live births) } \\
\hline 1 & \multicolumn{4}{|c|}{ Reference } & \multicolumn{4}{|c|}{ Reference } \\
\hline 2 & 0.89 & 0.42 & 0.67 & 1.18 & 0.82 & 0.20 & 0.60 & 1.11 \\
\hline 3 & 0.89 & 0.45 & 0.67 & 1.19 & 0.82 & 0.25 & 0.59 & 1.15 \\
\hline $4+$ & 1.04 & 0.73 & 0.82 & 1.32 & 0.88 & 0.46 & 0.62 & 1.24 \\
\hline \multicolumn{9}{|l|}{ Mother's education } \\
\hline No schooling & 2.09 & 0.000 & 1.64 & 2.66 & 1.76 & 0.000 & 1.30 & 2.37 \\
\hline $1-5$ years & 1.07 & 0.000 & 1.33 & 2.18 & 1.54 & 0.002 & 1.17 & 2.02 \\
\hline$>5$ years & \multicolumn{4}{|c|}{ Reference } & \multicolumn{4}{|c|}{ Reference } \\
\hline \multicolumn{9}{|l|}{ Husband's education } \\
\hline No schooling & 2.19 & 0.000 & 1.71 & 2.80 & 1.63 & 0.00 & 1.22 & 2.17 \\
\hline $1-5$ years & 1.60 & 0.001 & 1.22 & 2.09 & 1.23 & 0.16 & 0.92 & 1.64 \\
\hline$>5$ years & \multicolumn{4}{|c|}{ Reference } & Refer & & & \\
\hline Household wealth quintile & & & & & & & & \\
\hline Lowest & Refer & & & & Refer & & & \\
\hline Second & 0.83 & 0.24 & 0.60 & 1.14 & 0.71 & 0.04 & 0.51 & 0.98 \\
\hline Middle & 1.12 & 0.44 & 0.84 & 1.51 & 0.94 & 0.70 & 0.69 & 1.29 \\
\hline Fourth & 1.36 & 0.04 & 1.01 & 1.82 & 1.06 & 0.71 & 0.77 & 1.46 \\
\hline Highest & 0.87 & 0.37 & 0.63 & 1.19 & 0.73 & 0.06 & 0.52 & 1.02 \\
\hline Religion & & & & & & & & \\
\hline Islam & 1.53 & 0.05 & 0.99 & 2.38 & 1.63 & 0.04 & 1.03 & 2.57 \\
\hline Hindu/Others & Refer & & & & Refer & & & \\
\hline Father abused Mother & & & & & & & & \\
\hline Yes & 4.56 & 0.000 & 3.44 & 6.02 & 4.35 & 0.000 & 3.26 & 5.80 \\
\hline No & Refer & & & & Refer & & & \\
\hline Do not Know & 2.26 & 0.000 & 1.79 & 2.85 & 2.20 & 0.000 & 1.74 & 2.79 \\
\hline Members in household & & & & & & & & \\
\hline$<5$ & Refer & & & & Refer & & & \\
\hline $5-9$ & 0.98 & 0.87 & 0.80 & 1.21 & 0.99 & 0.93 & 0.80 & 1.23 \\
\hline $10+$ & 0.72 & 0.03 & 0.53 & 0.97 & 1.19 & 0.32 & 0.62 & 1.16 \\
\hline NGO member & & & & & & & & \\
\hline Yes & 1.44 & 0.01 & 1.10 & 1.88 & 1.38 & 0.03 & 1.04 & 1.82 \\
\hline No & Refer & & & & Refer & & & \\
\hline
\end{tabular}


Table 4 Women's perceived reasons for physical abuse by husband $(n=402)$

\begin{tabular}{lll}
\hline Perceived reasons for abuse & $\mathbf{n}$ & \% \\
\hline Without Reason & 262 & 65.2 \\
Financial Crisis & 92 & 22.9 \\
Disobeyed Husband/Elder & 86 & 21.4 \\
Neglected House Chores & 79 & 19.7 \\
Refused Sex & 57 & 14.2 \\
Bacause Husband Unemployed & 29 & 7.2 \\
Envy or Malice & 27 & 6.7 \\
Wife Suspects Infidelity & 21 & 5.2 \\
Food Crisis & 18 & 4.5 \\
For Dowry & 15 & 3.7 \\
Demand of Money From My Family & 14 & 3.5 \\
Went Out Without Permission & 5 & 1.2 \\
Husband Suspects Infidelity & 5 & 1.2 \\
Husband's Drug/Alcohol Use & 5 & 1.2 \\
Other & 4 & 1.0 \\
\hline
\end{tabular}

longitudinal, based on responses by women of different pregnancy status, findings did not suggest a reprieve of physical or sexual violence during pregnancy or postpartum as has been indicated by other research in Bangladesh [19, 31]. Moreover, we did not find a significant relationship between parity or number of household members and IPV.

It may seem counterintuitive that women who were members of an NGO or microfinancing organization had comparatively higher odds of having experienced

Table 5 Who physically abused (in past year) women told about experiences of IPV $(n=402)$

\begin{tabular}{|c|c|c|}
\hline Person told & $\mathbf{n}$ & $\%$ \\
\hline Anyone & 128 & 31.2 \\
\hline Mother/Father & 61 & 15.2 \\
\hline Mother-In-Law & 41 & 10.2 \\
\hline Neighbor & 37 & 9.2 \\
\hline Brother/Sister & 26 & 6.5 \\
\hline Father-In-Law & 20 & 5.0 \\
\hline Other Relative & 19 & 4.7 \\
\hline Aunt/Uncle & 15 & 3.4 \\
\hline Children & 7 & 1.7 \\
\hline Local Leader & 7 & 1.7 \\
\hline Friends & 3 & 0.7 \\
\hline Police & 2 & 0.5 \\
\hline Cleric & 2 & 0.5 \\
\hline Doctor/Healthworker & 1 & 0.2 \\
\hline Counselor & 1 & 0.2 \\
\hline Other & 1 & 0.2 \\
\hline
\end{tabular}

IPV in the past year, but perhaps the association could be explained by the explicit goal of NGOs to target the most vulnerable populations and lead to selection bias [57]. It is difficult to interpret this finding in a crosssectional study, where risks for reverse causality exist. For example, it is possible that women who experience IPV more commonly seek out NGOs for support. However, since our analysis did adjust for levels of wealth, education, and union (smallest administrative unit) membership, this finding is worthy of further consideration. One element that has been suggested for this particular context is that NGOs and microfinancing institutions in Bangladesh often include "women's empowerment" initiatives and microfinance programs for women. Such initiatives could possibly upset the balance of power in relationships and unintentionally lead to a period of increased violence and tension [25, 32, 58-60]. Based on recent quantitative and qualitative research, Murshid suggests that microfinance programming in Bangladesh should be coupled with IPV screening and intervention [33-35].

Poverty has been noted as a common risk factor for IPV $[21,27]$. Our study did not yield a significant association when examined by wealth quintile based on household assets. Interestingly, while wealth was not associated with IPV, financial crisis was given as a reason for having experienced physical or sexual violence by $23 \%$ of women who self-identified as having experienced violence in the past year. Perhaps, given that the majority of women in Bangladesh experience poverty, financial tension is a common occurrence across all wealth strata thereby reducing differentiation across wealth quintiles. Particular financial ups and downs within a wealth stratus may then be a more accurate predictor of IPV than the level of wealth per se. Alternatively, our methodology of accounting for wealth through household assets, which is a common method in developing countries, might not discriminate people into appropriate socioeconomic categories where poverty is widespread or be sensitive to seasonal trends or fluctuations in income that could give rise to stress or conflict. Additionally, household assets do not provide insight as to which household members are contributing funds, which might influence power dynamics and IPV. It could be true that wealth is not associated with IPV in our sample of women [16].

Disobedience, neglect of household chores, and refusal of sex were commonly cited as antecedents of physical abuse, which can be interpreted as typical characteristics of stringent gender roles within a patriarchal system [24, $26,61,62]$. We found that $65 \%$ of women who had experienced violence in the past year indicated that they had experienced abuse without a particular antecedent. In a sample of 496 ever-married Bangladeshi women, Yount and colleagues (2013) found that women (38-68\%) 
justified abuse by the husband when the woman's transgression was depicted as willful, especially disobeying elders in the marital family (68\%), neglecting the children (65\%), and arguing with the husband (59\%). Conversely, relatively fewer women (1-8\%) justified wife hitting or beating when her transgression, as perceived by the perpetrator, was depicted as unintended [24].

Approximately one in three women (31.2\%), who experienced IPV, shared their experience with others. Considering the possibility that some abused women interviewed in our study may have withheld their experiences with IPV, it appears that most women in our study population experiencing IPV are never assisted in any way. Sharing with or pursuit of formal avenues (police, counselors, health workers, etc.) for assistance with IPV was virtually non-existent $(<1 \%)$.

Our study is not without limitations. Due to the crosssectional nature of this study, factors associated with IPV may not be causal. Our statistical modeling for factors did not include all possible covariates. For example, it is common for Sylheti men to migrate for work, which subsequently reduces the probability of IPV. While the unions surveyed in this study were typical of rural Bangladesh, characteristics did vary by union and generalizability of the results may be limited. The possibility of reporting bias in our study is of concern, particularly given that we found a lower prevalence of IPV than other studies conducted in Bangladesh. IPV could have been underreported due to many factors, such as fear of repercussions, shame, or loss to follow-up of women most at risk for abuse. Our study survey was conducted years after a live birth, thereby excluding newlyweds and women without children.

Though IPV affects a large proportion of the women directly and everyone indirectly, minimal research and few resources have been dedicated to addressing the enormous problem in Sylhet, Bangladesh. Our study documents that a large proportion of women of reproductive age in rural Bangladesh suffers from the atrocities of IPV. In 1993, the United Nations General Assembly declared, "We must ensure zero tolerance of violence against or exploitation of women and girls [63]." The Millennium Development Goals (MDGs) and newly established Sustainable Development Goals (SDGs) stress gender equality, women's empowerment, and improvement of maternal health.

The need for prevention of IPV and efforts to reduce IPV where it occurs, are clear. Generational transfer of IPV is evident and demonstrates that families, in and of themselves, are not likely to break the cycle of abuse automatically. Based on a 2014 review of interventions to reduce violence against women in LMICs, interventions designed to prevent IPV should be multifaceted, address risk-factors, and engage many stakeholders [64]. Specifically, for Sylhet, interventions should target women with a history of parental IPV, as well as younger, and lesser-educated couples. Ideally, primary prevention should exist prior to marriage. Those who had obtained little education were most probable for perpetrating violence (husbands) and experiencing violence (wives). Limiting primary prevention to school settings alone would neglect vast majority of at-risk populations. Multisectoral programs enabling community engagement and participatory approaches to address cultural attitudes and behaviors towards IPV have been found to be effective [64]. In our study, most women who experienced IPV did not tell anyone and pursuit of formal avenues for help was highly unlikely. Addressing the multiple stakeholders and equipping both informal and formal avenues of assistance can lead to positive change [64]. Social and/or economic interventions to reduce IPV in LMICs have been associated with decreases in controlling behaviors by partners, relationship quality improvements, and economic gains [65]. Based on our study finding that NGO membership was a risk factor for IPV, caution is warranted when conducting interventions. Future research on effective IPV prevention and reduction strategies is urgently needed.

\section{Abbreviations \\ IPV: Intimate partner violence; WHO: World Health Organization; NGO: Non- Governmental Organization; HFS: Healthy Fertility Study; CHW: Community health worker; BDHS: Bangladesh Demographic Health Survey}

\section{Acknowledgements}

The authors are grateful for the support and contributions of Dr. Ishtiaq Mannan, Angela Nash-Mercado, Robin Anthony Kouyate, Berengere de Negri, and Carla Blauvelt. The authors thank the study participants and field staff for their efforts in implementing the study and delivering the intervention, and the Ministry of Health and Family Welfare, Government of Bangladesh, for their support and collaboration in all phases of the study.

\section{Authors' contributions}

Stephen Stake-conception, interpretation of data, drafting, critical revision. Saifuddin Ahmed-conception, data collection, interpretation of data, critical revision. Wietse Tol_conception, interpretation of data, critical revision. Salahuddin Ahmed_conception, study design. Nazma Begum—data collection. Rasheda Khanam-critical revision. Meagan Harrison-critical revision and formatting. Abdullah Baqui-conception, data collection, interpretation of data, critical revision. All authors read and approved the final manuscript.

\section{Funding}

Funding for this study was made possible through support provided by U.S. Agency for International Development/Bangladesh and the Office of Population and Reproductive Health, U.S. Agency for International Development/Washington D.C., under the terms of Award No GHS-A-00-0800002-00 (Maternal and Child Health Integrated Program (MCHIP)-Leader with Associates Cooperative Agreement), No. GPO-AA-05-00025-00 (Associate Cooperative Agreement with the Access Program), No. GHS-A-00-04-0000200 (Reference Leader Cooperative Agreement with the Access Program), and No. GHS-A-00-03-00019-00 (Global Research Activity Cooperative Agreement with the Johns Hopkins Bloomberg School of Public Health). 


\section{Availability of data and materials}

De-identified data is available. The datasets used and/or analyzed during the current study are available from the corresponding author upon reasonable request.

\section{Ethics approval and consent to participate}

The primary study as described was approved by the Institutional Review Board of the Johns Hopkins Bloomberg School of Public Health and the National Research Ethics Committee of Bangladesh Medical Research Council (BMRC) and was registered under clinical trial registry. Consent was obtained by each participant.

\section{Consent for publication}

Not applicable

\section{Competing interests}

The views expressed in this manuscript are from the authors, and are not an official position of the Johns Hopkins University Bloomberg School of Public Health or the study funders. The authors declare that they have no competing interests.

\section{Author details}

'Johns Hopkins Bloomberg School of Public Health, Room E-8153, 615 N. Wolfe Street, Baltimore, MD 21205, USA. ${ }^{2} K^{\prime} i m a: w$ Medical Center, 535 Airport Rd., Hoopa, CA 95546, USA. ${ }^{3}$ Peter C. Alderman Program for Global Mental Health, HealthRight International, 14 E 4th Street, 3rd Floor, New York, NY 10012, USA.

\section{Received: 21 January 2020 Accepted: 23 November 2020} Published online: 07 December 2020

\section{References}

1. Krug M. Dahlberg, Zwi world report on violence and health. Lancet. 2002; 360:1083-8.

2. WHO. Global and regional estimates of violence against women: prevalence and health effects of intimate partner violence and non-partner sexual violence. World Health Organization 2013.

3. Ellsberg $M$, Jansen HA, Heise $L$, et al. Intimate partner violence and women's physical and mental health in the WHO multi-country study on women's health and domestic violence: an observational study. Lancet. 2008; 371(9619):1165-72. https://doi.org/10.1016/S0140-6736(08)60522-X.

4. Devries KM, Mak JY, Bacchus $L$, et al. Intimate partner violence and incident depressive symptoms and suicide attempts: a systematic review of longitudinal studies. PLoS Med. 2013;10(5):e1001439. https://doi.org/10. 1371/journal.pmed.1001439.

5. Dillon G, Hussain R, Loxton D, et al. Mental and physical health and intimate partner violence against women: a review of the literature. Int J Family Med. 2013:2013:313909. https://doi.org/10.1155/2013/313909.

6. Garcia-Moreno. Global and regional estimates of violence against women: prevalence and health effects of intimate partner violence and nonpartner sexual violence. 2013.

7. Felitti VJ, Anda RF, Nordenberg D, et al. Relationship of childhood abuse and household dysfunction to many of the leading causes of death in adults. The adverse childhood experiences (ACE) study. Am J Prev Med. 1998;14(4):245-58

8. Walker EA, Gelfand A, Katon WJ, et al. Adult health status of women with histories of childhood abuse and neglect. Am J Med. 1999;107(4):332-9.

9. Rees SJ, Tol W, Mohammad M, et al. A high-risk group of pregnant women with elevated levels of conflict-related trauma, intimate partner violence, symptoms of depression and other forms of mental distress in post-conflict Timor-Leste. Transl Psychiatry 2016;6:e767. doi: https://doi.org/10.1038/tp. 2016.33 [published Online First: 2016/03/31].

10. Campbell JC, Lewandowski LA. Mental and physical health effects of intimate partner violence on women and children. Psychiatr Clin North Am. 1997;20(2):353-74

11. Jejeebhoy SJ. Associations between wife-beating and fetal and infant death: impressions from a survey in rural India. Stud Fam Plan. 1998;29(3):300-8.

12. Silverman JG, Decker MR, Gupta J, et al. Maternal experiences of intimate partner violence and child morbidity in Bangladesh: evidence from a national Bangladeshi sample. Arch Pediatr Adolesc Med. 2009;163(8):700-5. https://doi.org/10.1001/archpediatrics.2009.115.
13. Ahmed S, Koenig MA, Stephenson R. Effects of domestic violence on perinatal and early-childhood mortality: evidence from North India. Am J Public Health. 2006;96(8):1423-8. https://doi.org/10.2105/AJPH.2005.066316.

14. Garcia-Moreno C, Jansen HA, Ellsberg M, et al. Prevalence of intimate partner violence: findings from the WHO multi-country study on women's health and domestic violence. Lancet. 2006;368(9543):1260-9. https://doi. org/10.1016/S0140-6736(06)69523-8.

15. Asling-Monemi K, Naved RT, Persson LA. Violence against women and increases in the risk of diarrheal disease and respiratory tract infections in infancy: a prospective cohort study in Bangladesh. Arch Pediatr Adolesc Med. 2009;163(10):931-6. https://doi.org/10.1001/archpediatrics.2009.167.

16. Bates LM, Schuler SR, Islam F, et al. Socioeconomic factors and processes associated with domestic violence in rural Bangladesh. Int Fam Plan Perspect. 2004;30(4):190-9. https://doi.org/10.1363/ifpp.30.139.04.

17. Decker MR, Miller $E$, Kapur NA, et al. Intimate partner violence and sexually transmitted disease symptoms in a national sample of married Bangladeshi women. Int J Gynaecol Obstet. 2008;100(1):18-23. https:/doi.org/10.1016/j.jigo.2007.06.045.

18. Fulu $E$, Jewkes $R$, Roselli $T$, et al. Prevalence of and factors associated with male perpetration of intimate partner violence: findings from the UN multicountry cross-sectional study on men and violence in Asia and the Pacific. Lancet Glob Health. 2013;1(4):e187-207. https://doi.org/10.1016/S2214109X(13)70074-3.

19. Kabir ZN, Nasreen HE, Edhborg M. Intimate partner violence and its association with maternal depressive symptoms 6-8 months after childbirth in rural Bangladesh. Glob Health Action. 2014;7:24725. https://doi.org/10. 3402/gha.v7.24725.

20. Naved RT, Azim S, Bhuiya A, et al. Physical violence by husbands: magnitude, disclosure and help-seeking behavior of women in Bangladesh. Soc Sci Med. 2006;62(12):2917-29. https://doi.org/10.1016/j.socscimed.2005.12.001.

21. Sambisa W, Angeles G, Lance PM, et al. Prevalence and correlates of physical spousal violence against women in slum and nonslum areas of urban Bangladesh. J Interper Viol. 2011;26(13):2592-618. https://doi.org/10. 1177/0886260510388282.

22. National Institute of Population Research and Training (NIPORT) MaA, and Macro International. Bangladesh Demographic and Health Survey 2007. Dhaka, Bangladesh and Calverton, Maryland, USA National Institute of Population Research and Training, Mitra and Associates, and Macro International, 2009.

23. Johnson MP. A typology of domestic violence: intimate terrorism, violent resistance, and Situtional couple violence. Boston: University Press of New England; 2008.

24. Yount KM, Halim N, Schuler SR, et al. A survey experiment of women's attitudes about intimate partner violence against women in rural Bangladesh. Demography. 2013;50(1):333-57. https://doi.org/10.1007/ s13524-012-0143-7.

25. Schuler SR, Lenzi R, Yount KM. Justification of intimate partner violence in rural Bangladesh: what survey questions fail to capture. Stud Fam Plan. 2011:42(1):21-8.

26. Schuler SR, Yount KM, Lenzi R. Justification of wife beating in rural Bangladesh: a qualitative analysis of gender differences in responses to survey questions. Violence Against Women. 2012;18(10):1177-91. https://doi. org/10.1177/1077801212465152.

27. Naved RT, Persson LA. Factors associated with spousal physical violence against women in Bangladesh. Stud Fam Plan. 2005;36(4):289-300.

28. Rahman M, Nakamura K, Seino K, et al. Intimate partner violence and chronic undernutrition among married Bangladeshi women of reproductive age: are the poor uniquely disadvantaged? Eur J Clin Nutr. 2013;67(3):301-7. https://doi.org/10.1038/ejcn.2012.202.

29. Rapp D, Zoch B, Khan MM, et al. Association between gap in spousal education and domestic violence in India and Bangladesh. BMC Public Health. 2012;12:467. https://doi.org/10.1186/1471-2458-12-467.

30. Dalal K, Rahman F, Jansson B. Wife abuse in rural Bangladesh. J Biosoc Sci. 2009;41(5):561-73. https://doi.org/10.1017/S0021932009990046.

31. Naved RT, Persson LA. Factors associated with physical spousal abuse of women during pregnancy in Bangladesh. Int Fam Plan Perspect. 2008;34(2): 71-8. https://doi.org/10.1363/ifpp.34.071.08.

32. Koenig MA, Ahmed S, Hossain MB, et al. Women's status and domestic violence in rural Bangladesh: individual- and community-level effects. Demography. 2003:40(2):269-88.

33. Murshid NS. Men's response to their wives' participation in microfinance: perpetration and justification of intimate partner violence in Bangladesh. Public Health. 2016;141:146-52. https://doi.org/10.1016/j.puhe.2016.09.016. 
34. Murshid NS, Akincigil A, Zippay A. Microfinance participation and domestic violence in Bangladesh: results from a nationally representative survey. J Interpers Violence. 2016;31(9):1579-96. https://doi.org/10.1177/ 0886260515569065

35. Murshid NS, Zippay A. Microfinance participation and marital violence in Bangladesh: a qualitative inquiry. Violence Against Women. 2016. https:// doi.org/10.1177/1077801216665480.

36. Black SS, Unger JB. A further look at the intergenerational transmission of violence: witnessing interparental violence in emerging adulthood. J Interpers Violence. 2010;25(6):1022-42. https://doi.org/10.1177/ 0886260509340539.

37. Black DEA. Partner, child abuse risk factors literature review. 1999. http:// www.nnh.org/risk.

38. Perales MT, Cripe SM, Lam N, et al. Prevalence, types, and pattern of intimate partner violence among pregnant women in Lima, Peru. Violence Against Women. 2009;15(2):224-50. https://doi.org/10.1177/ 1077801208329387.

39. Rahman M, Sasagawa T, Fujii R, et al. Intimate partner violence and unintended pregnancy among Bangladeshi women. J Interpers Violence. 2012;27(15):2999-3015. https://doi.org/10.1177/0886260512441072.

40. Wahed T, Bhuiya A. Battered bodies \& shattered minds: violence against women in Bangladesh. Indian J Med Res 2007;126(4):341-54. [published Online First: 2007/11/23].

41. National Institute of Population Research and Training (NIPORT) MaA, and ICF International. Bangladesh Demographic and Health Survey 2014. Dhaka, Bangladesh, and Rockville, Maryland, USA:: NIPORT, Mitra and Associates, and ICF International 2016.

42. Bhuiyan R. Aspect of violence against women. Institute of Democratic Rights,13, Dhanmondhi Residential Area, Dhaka, Bangladesh, 1991

43. Hasam M, Mushahid M, Afrose D. The existing Laws regarding punishment for household violence against females in Bangladesh: a study on the perception of educated class. Res Humanit Soc Sci. 2017:7:2225-484.

44. Ali TS, Mogren I, Krantz G. Intimate partner violence and mental health effects: a population-based study among married women in Karachi, Pakistan. Int J Behav Med 2013;20(1):131-9. doi: https://doi.org/10.1007/ s12529-011-9201-6 [published Online First: 2011/11/01]

45. Ashrafun L. Seeking a way out of the cage: underprivileged women and domestic violence in Bangladesh. PhD diss., Publications of the Department of Social Research 3, The Helsinki University Press, Helsinki., 2013.

46. Okenwa LE, Lawoko S, Jansson B. Factors associated with disclosure of intimate partner violence among women in Lagos, Nigeria. J Injury Viol Res. 2009;1(1):37-47. https://doi.org/10.5249/jivr.v1i1.15.

47. Marium S. Women's level of education and its effect on domestic violence in rural Bangladesh. IOSR J Human Soc Sci. 2014;19(5):40-5.

48. Ahmed S, Ahmed S, McKaig C, et al. The effect of integrating family planning with a maternal and newborn health program on postpartum contraceptive use and optimal birth spacing in rural Bangladesh. Stud Fam Plan. 2015;46(3):297-312. https://doi.org/10.1111/j.1728-4465.2015.00031.x.

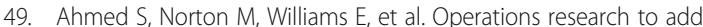
postpartum family planning to maternal and neonatal health to improve birth spacing in Sylhet District, Bangladesh. Global Health Sci Practice. 2013; 1(2):262-76. https://doi.org/10.9745/GHSP-D-13-00002.

50. Merlo J, Chaix B, Ohlsson $\mathrm{H}$, et al. A brief conceptual tutorial of multilevel analysis in social epidemiology: using measures of clustering in multilevel logistic regression to investigate contextual phenomena. J Epidemiol Community Health. 2006;60(4):290-7. https://doi.org/10.1136/jech.2004. 029454.

51. Islam MJ, Broidy L, Baird K, et al. Intimate partner violence around the time of pregnancy and postpartum depression: The experience of women of Bangladesh. PLoS One 2017;12(5):e0176211. doi: https://doi.org/10.1371/ journal.pone.0176211 [published Online First: 2017/05/05].

52. Sagrestano LM, Heavey CL, Christensen A. Perceived power and physical violence in marital conflict. J Soc Issues. 1999;55(1):65-79. https://doi.org/10. 1111/0022-4537.00105.

53. Bell KM, Naugle AE. Intimate partner violence theoretical considerations: moving towards a contextual framework. Clin Psychol Rev. 2008;28(7):1096107. https://doi.org/10.1016/j.cpr.2008.03.003

54. Flynn A, Graham K. "why did it happen?" a review and conceptual framework for research on perpetrators' and victims' explanations for intimate partner violence. Aggress Violent Behav. 2010;15(3):239-51. https:// doi.org/10.1016/j.avb.2010.01.002.
55. Boyle MH, Georgiades K, Cullen J, et al. Community influences on intimate partner violence in India: Women's education, attitudes towards mistreatment and standards of living. Soc Sci Med. 2009;69(5):691-7. https:// doi.org/10.1016/j.socscimed.2009.06.039.

56. Johnston HB, Naved RT. Spousal violence in Bangladesh: a call for a publichealth response. J Health Popul Nutr 2008;26(3):366-77. [published Online First: 2008/10/04]

57. Bajracharya A, Amin S. Microcredit and domestic violence in Bangladesh: an exploration of selection bias influences. Demography. 2013;50(5):1819-43. https://doi.org/10.1007/s13524-013-0226-0.

58. McClennen. Social work and family violence. New York: Springer Publishing; 2010.

59. Schuler SR, Hashemi SM, Badal SH. Men's violence against women in rural Bangladesh: undermined or exacerbated by microcredit programmes? Dev Pract. 1998:8(2):148-57. https://doi.org/10.1080/09614529853774.

60. Schuler SR, Hashemi SM, Riley AP, et al. Credit programs, patriarchy and men's violence against women in rural Bangladesh. Soc Sci Med. 1996; 43(12):1729-42.

61. Johnson M. A "general" theory of intimate partner violence: a working paper; 2006.

62. Kandiyoti D. Bargaining with patriarchy. Gend Soc. 1988;2(3):274-90

63. UN. Declaration on the Elimination of Violence against Women. United Nations General Assembly: United Nations General Assembly, 1993.

64. Ellsberg $M$, Arango DJ, Morton $M$, et al. Prevention of violence against women and girls: what does the evidence say? Lancet 2015;385(9977):155566. doi: https://doi.org/10.1016/S0140-6736(14)61703-7 [published Online First: 2014/12/04]

65. Bourey C, Williams W, Bernstein EE, et al. Systematic review of structural interventions for intimate partner violence in low- and middle-income countries: organizing evidence for prevention. BMC Public Health 2015;15: 1165. doi: https://doi.org/10.1186/s12889-015-2460-4 [published Online First: 2015/11/26].

\section{Publisher's Note}

Springer Nature remains neutral with regard to jurisdictional claims in published maps and institutional affiliations.

Ready to submit your research? Choose BMC and benefit from:

- fast, convenient online submission

- thorough peer review by experienced researchers in your field

- rapid publication on acceptance

- support for research data, including large and complex data types

- gold Open Access which fosters wider collaboration and increased citations

- maximum visibility for your research: over $100 \mathrm{M}$ website views per year

At $\mathrm{BMC}$, research is always in progress.

Learn more biomedcentral.com/submissions 